\title{
A novel strategy for the targeted analysis of protein and peptide metabolites
}

\author{
Nicholas A. Williamson ${ }^{1},{ }^{*}$, Charles Reilly ${ }^{1}$, Chor-Teck Tan ${ }^{1}$, Sri-Harsha Ramarathinam ${ }^{1}$, \\ Alun Jones $^{2}$, Christie L. Hunter ${ }^{3}$, Francis R. Rooney ${ }^{4}$, and Anthony W. Purcell ${ }^{1,{ }^{*}}$ \\ ${ }^{1}$ Department of Biochemistry and Molecular Biology, The Bio21 Molecular Science and \\ Biotechnology Institute, The University of Melbourne, Parkville, Victoria, 3010 Australia \\ ${ }^{2}$ Institute for Molecular Bioscience, The University of Queensland, Brisbane, Queensland, 4072, \\ Australia \\ ${ }^{3}$ AB SCIEX, 850 Lincoln Centre Drive, Foster City, 94404, CA, USA \\ ${ }^{4}$ AB SCIEX, 52 Rocco Drive, Scoresby, Victoria, 3179, Australia
}

\section{Abstract}

In many biological applications such as epitope discovery or drug metabolism studies the detection of naturally processed exogenous proteins (e.g. vaccines or peptide therapeutics) and their metabolites is frequently complicated by the presence of a complex endogenous mixture of closely related or even identical compounds. We describe a method that incorporates stable isotope labelling of the protein of interest allowing the selective screening of the intact molecule and all metabolites using a modified precursor ion scan. This method involves monitoring the low molecular weight fragment ions produced during MS/MS that distinguish isotopically labelled peptides from related endogenous compounds. All isotopically labelled peptides can be selected using this method. The technique makes no assumptions about the processed or posttranslational state of the peptide, and can hence can selectively screen out modified peptides that would otherwise be missed by SRM approaches. This method does not replace SRM or regular precursor scanning techniques; instead it is a method that can be used when the assumptions required for the former two techniques cannot be predicted. The potential for this technique to be used in metabolism and pharmacokinetic experiments is discussed with specific examples looking at the metabolism of a-synuclein in serum and the brain.

\section{Keywords \\ ${ }^{15} \mathrm{~N}$ Precursor scanning; immonium ion; selective peptide detection; ADME; DMPK}

\section{Introduction}

It is often necessary to distinguish a target peptide from a mixture of other closely related species within a wide range of analyte concentrations. Mass spectrometry is frequently the method of choice for such analyses as it can selectively identify peptides by their precursor ion mass and/or by using their fragment ion (product ion) spectra [1]. However the complexity of many biological samples often results in the simultaneous production of

\footnotetext{
*Address all correspondence to AWP Phone +613 8344 2288, Fax +613 9348 1421, apurcell@unimelb.edu.au or NAW Phone +613 8344 2206, Fax+6139348 1421, nawill@unimelb.edu.au.

Conflict of interest statement: The methodology described herein is the subject of Patent WO/2008/142579. We are currently seeking a commercial partner for further development of the technique. No other conflicts exist.
} 
multiple precursors, even with on-line separation techniques such as during LC-MS. Most modern instruments can readily manage this situation and given sufficient time can systematically attempt to characterize one ion after another until all the available components are sampled. The disadvantage of this technique is the time taken to analyse each precursor, which in the case of very complex samples may be longer than the analyte is available (e.g. during the duration of a chromatographic peak in which the analyte(s) are contained during an LC-MS experiment).

There are two targeted mass spectrometry techniques to more specifically detect specific peptides from a mixture. The first is "single reaction monitoring" (SRM) or "multiple reaction monitoring" (MRM) where the mass spectrometer is configured to only detect molecules of a defined precursor $\mathrm{m} / \mathrm{z}$ (mass), ignoring or excluding all others, allowing molecules of known mass to be identified with very high sensitivity [2]. In complex mixtures it is particularly desirable to use additional information about the targeted molecule to identify it from closely related species of similar or identical mass. Thus the mass spectrometer is configured to monitor for the presence of a specific product ion that is formed by the fragmentation of a targeted precursor ion; for example monitoring the intensity of a specific $b$ ion formed by the fragmentation of a known peptide precursor.

The second technique for detection of target compounds in a complex mixture is called "precursor ion scanning" or "parent ion scan". In this instance prior knowledge of the molecule may not extend to knowledge of the precursor mass, but the molecule may be known to contain a certain component that would result in the presence of a diagnostic product ion. For example, Wilm et al. [3] report the detection of peptides at low femtomole levels using precursor ion scans by monitoring for the presence of the Leucine/Isoleucine immonium ions. They also demonstrated the selective detection of different subsets of tryptic peptides by using the $\mathrm{y}_{1}$ ion corresponding to respective Arginine or Lysine Cterminal residues, and the selective detection of phosphopeptides from a mixture by targeting the ion corresponding to $\mathrm{PO}_{3}{ }^{-}$loss $(\mathrm{m} / \mathrm{z}-79)$. These examples highlight the utility of this well established technique [4-7] to perform targeted proteomic analysis on classes of peptides based on their generation of a unique fragment ion during MS/MS.

Both precursor scanning and SRM/MRM are limited by the necessity to have knowledge of the target precursor mass and/or the product ion mass for the class of molecules or the molecule of interest [1]. In a complex biological system often it is impossible to predict the mass of the natural form of a target peptide. This may be due to post-translational modification of the peptide, natural proteolytic processing or metabolism of the peptide from the parent biomolecule. This problem can be overcome to some extent by performing multiple precursor scans or MRM transitions, however the peptides "discovered" will always be limited by the assumptions regarding precursor $\mathrm{m} / \mathrm{z}$ or product ion masses monitored in the respective experiments. Also, in many instances the total number of potential metabolites is so large that it becomes impractical to monitor all the possible MRM transitions to cover the candidate metabolites. It is therefore desirable to have an analytical technique which can selectively screen out target peptides from a complex mixture, in real time, that does not require the same assumptions as an MRM or precursor scan.

One approach to overcoming this problem has involved the use stable isotope labelling to enable the identification of naturally processed forms of proteins in complex biological mixtures. For example the identification of peptide epitopes derived from isotopically labelled protein antigens [8]. In this approach a search engine is used to retrospectively interrogate the data to identify isotopically labelled (i.e. antigen derived) peptides that were observed in the first analytical run and then a second experiment is used to sequence the target peptides using an inclusion list for MS\MS analysis. The necessity to use multiple LC 
runs for the same sample makes this approach cumbersome and restricts identification of low abundance peptides. For very complex samples there is also the complication of coeluting isobaric peptides that would interfere with the identification process.

Here we describe a variation of a precursor ion scan in conjunction with stable isotope labelling that allows real time discrimination of isotopically labelled material and triggers further MS/MS analysis for the identification and characterisation of these species. In this instance we assume that a target peptide derived from a uniformly ${ }^{15} \mathrm{~N}$ labelled protein will produce one or more characteristic fragment ions, such as ${ }^{15} \mathrm{~N}$ containing immonium ions, in the low mass region of the product ion spectra [9-10]. These ions can be used as the diagnostic ions for a precursor scan. We have termed this technique NIIPe, ${ }^{15} \mathrm{~N}$ Immonium Ion Precursor scanning. We have shown that using this technique we can successfully screen ${ }^{15} \mathrm{~N}$ labelled peptides from a complex mixture of more abundant unlabelled peptides. Furthermore, even though the instrument selection process may occasionally falsely select a non target peptide they are easily identified as unlabelled and ignored in subsequent data analysis. This technique will have application in any mass spectrometry experiment where the prerequisite knowledge for an MRM or precursor scan cannot be met. The technique also has the further advantage that peptides from the original protein can still be identified irrespective of what types of processing or modification the peptide underwent affording new levels of coverage in DMPK and other monitoring technologies.

\section{Materials and Methods}

\subsection{Sample preparation}

${ }^{15} \mathrm{~N} \mathrm{a}$-synuclein was a gift from Dr Roberto Cappai, Department of Pathology, University of Melbourne. ${ }^{15} \mathrm{~N}$ DHDPS was a gift from Dr Renwick Dobson, Department of Biochemistry and Molecular Biology, University of Melbourne. BSA was from SigmaAldrich (St. Louis, MO). Proteins were resuspended in $50 \mathrm{mM}$ TEAB and digested for $24 \mathrm{hr}$ at $37^{\circ} \mathrm{C}$, using proteomics grade Trypsin, LysC or endoprotease GluC at a ratio of 50:1 by mass. For the BSA a-synuclein experiment a $1 \mathrm{mg} / \mathrm{ml}$ BSA trypsin digest was spiked with an equal volume of $1 \mathrm{mg} / \mathrm{ml}{ }^{15} \mathrm{~N}$ a-synuclein LysC digest. The mouse thymus MHC peptide mixture was prepared by acid extraction as described elsewhere [11-12]. Trypsin digested ${ }^{15} \mathrm{~N}$ DHDPS was spiked into $40 \mu \mathrm{g}$ of mouse thymus MHC peptide lysate. For asynuclein experiments $5 \mathrm{nmol}$ of ${ }^{15} \mathrm{~N}$ a-synuclein was added to $1 \mathrm{ml}$ of neat serum or $1 \mathrm{ml}$ of crude brain homogenate ( 1 mouse brain homogenised [mortar and pestle] in TBS to a volume of $1 \mathrm{ml}$ ). Proteins were precipitated by the addition of 4 volumes of $20 \%$ trichloroacetic acid on ice. Protein precipitate was removed by benchtop centrifugation at $16000 \times \mathrm{g}$ and the remaining supernatant analysed by mass spectrometry. Animal experiments were performed under NHMRC guidelines and were approved by the University of Melbourne Animal Ethics Committee (ethics approval AEC-0702440).

\subsection{Mass Spectrometry}

QTOF analysis of the low mass region for ${ }^{15} \mathrm{~N} \mathrm{a}$-synuclein was carried out using an $\mathrm{AB}$ SCIEX QSTAR Elite Hybrid LC-MS/MS fitted with a nanospray II ionsource (distal coated new objective spray tip at 2400V) coupled with an Eksigent Tempo ${ }^{\mathrm{TM}}$ nanoflow LC $10 \mathrm{pmol}$ of ${ }^{15} \mathrm{~N}$ a-synuclein LysC digest was loaded onto a $300 \mu \mathrm{m}$ C18 trap column and further separated by a $75 \mu \mathrm{m} \times 10 \mathrm{~cm}$ C18 column (SGE Australia) using a $45 \mathrm{~min}, 2-60 \%$ Acetonitrile/ $0.1 \%$ Formic acid gradient. Data dependent acquisition was performed on ions between the mass range of $370-1400 \mathrm{Da}$ with an intensity threshold of $>20 \mathrm{cps}$ and product ion scans that covered the mass range of $68-1800 \mathrm{Da}$ 


\subsection{QTRAP experiments}

Samples were loaded onto a $300 \mu \mathrm{m} \times 10 \mathrm{~mm}$ C18 trap column and further separated by a $300 \mu \mathrm{m} \times 10 \mathrm{~cm}$ C18 column (SGE Australia) using a $75 \mathrm{~min}$, linear 2-60\% Acetonitrile/ $0.1 \%$ Formic acid gradient delivered by a Dionex UltiMate 3000 capillary HPLC system at $8 \mu \mathrm{l} / \mathrm{min}$. Eluting peptides were analysed using an AB SCIEX 4000 QTRAP instrument fitted with a Turbo $\mathrm{V}$ ion source. For the immonium ion precursor scans, multiple 6 second precursor scans were performed using a collision energy ramp of 25 to $50 \mathrm{eV}$ for a mass range of 400-1000 Da with a step size of 1.0 amu. Q1 resolution was set to low and Q3 was set to unit resolution. Automated MS/MS selection was performed with an intensity threshold of $1.00 \mathrm{cps}$ and triggered three enhanced product ion scans. These were performed using $Q_{0}$ trapping and rolling collision energy, scanning the mass range of 69-1500 Da with a LIT fill time of 40ms. A single MS scan was also looped into the method to provide more information for later analysis of the precursors available for selection. Total cycle time was $\sim 28$ s for 4 precursor or $\sim 20$ s for a triple precursor and $\sim 15$ s for a double precursor scan. Conventional LC-MS/MS experiments using the 4000 QTRAP were performed using the same chromatographic and ion source parameters as the precursor scan. A survey scan monitored masses from m/z 400 to 1600 and automated MS/MS was employed to target the top 2 precursors per scan, using rolling collision energy, $Q_{0}$ trapping, intensity threshold $1,000 \mathrm{cps}$, excluding former target ions for $60 \mathrm{~s}$, LIT fill time $50 \mathrm{~ms}$.

\subsection{Data analysis}

All the mass spectrometry data sets were analysed manually to ensure all ${ }^{15} \mathrm{~N}$ peptides were detected and assigned correctly. At the time of performing these experiments we noted that most of the available software tools failed to reliably work with ${ }^{15} \mathrm{~N}$ labelled peptides. Thus, each product ion spectrum was manually assessed (in particular observing the low mass region) and wherever possible compared back to earlier digest results for the ${ }^{15} \mathrm{~N}$ labelled protein alone e.g. retention time, fragmentation pattern etc. We note that several software algorithms have recently adopted the ability to assign raw MS/MS data from uniformly labelled ${ }^{15} \mathrm{~N}$-labelled peptides including MASCOT and ProteinPilot.

\section{Results}

\section{$3.1^{15} \mathrm{~N}$ labelled peptides can be screened from regular peptides by monitoring for diagnostic ${ }^{15} \mathrm{~N}$ low mass ions}

The principal of precursor ion scanning is very useful as it screens out those ions that do not meet the selection criteria. All that is required is a suitable diagnostic ion that can be used to define the presence of the target compound or class of compounds. We and others [3,13] have shown that the low mass region of the product ion spectrum contains ions that could be used to distinguish different classes of peptides. We further elaborate on this idea by introducing the concept that for ${ }^{15} \mathrm{~N}$ labelled peptides, diagnostic low mass ions can be used to distinguish these isotopically labelled species from endogenous peptides. In particular, all immonium ions [9] contain at least one nitrogen and hence all immonium ions formed from a ${ }^{15} \mathrm{~N}$ labelled peptide will display a mass shift of at least $1 \mathrm{amu}$. A calculation of the mass of all the ${ }^{15} \mathrm{~N}$ immonium ions compared to all the unlabelled immonium ions revealed that, with the exception of ${ }^{15} \mathrm{~N}$ Leu/lle overlapping with unlabelled Asn, they produced unique immonium ion masses (Table 1). Additional overlap with other low mass related ions are also few with many of the related ion masses in Table 1 not routinely observed or instrument dependent [10]. Indeed, MS $\backslash$ MS of ${ }^{15} \mathrm{~N}$ labelled peptides produced distinctive product ion species (Fig. 1) and highlights the potential to use these differences to discriminate labelled from unlabelled peptides during a precursor scan. At its simplest one ${ }^{15} \mathrm{~N}$ immonium or related ion could be used as a target for a precursor scan while a more sophisticated 
approach would monitor the entire low mass region for patterns diagnostic for ${ }^{15} \mathrm{~N}$ peptides (thereby providing further specificity and reducing the possibility of false selection).

A ${ }^{15} \mathrm{~N}$ precursor ion scan can be performed using any triple quadrupole mass spectrometer which is able to target a single fragment ion and then scan for precursor masses that give rise to the target ion. Thus ${ }^{15} \mathrm{~N}$ peptides could be screened from a mixture by using, for example, the mass of the ${ }^{15} \mathrm{~N}$ immonium ion of valine at $\mathrm{m} / \mathrm{z} 73$. As shown in Figure 2, a series of ${ }^{15} \mathrm{~N}$ targeted precursor scans successfully screened ${ }^{15} \mathrm{~N}$ labelled $\mathrm{a}$-synuclein peptides from a mixture also containing unlabelled BSA tryptic peptides. The full complexity of the peptide mixture is revealed by the base peak chromatogram representation of the LC-MS experiment (Fig 2A). As expected each of the three scans screened out a different subset of a-synuclein peptides and ignored most of the BSA peptides (Fig. 2B-D). The precursor scan of 73 detected peptides that generated a ${ }^{15} \mathrm{~N}$-Valine immonium ion $\left(\mathrm{L}_{3-5}, \mathrm{~L}_{8}, \mathrm{~L}_{10}, \mathrm{~L}_{12}\right.$ : supplementary Table 1), representing all but two valine containing peptides present in the sample. The peak marked with an asterisk most likely represents the $\mathrm{L}_{1}$ fragment however MS/MS verification was not possible. An $\mathrm{L}_{13}$ fragment was not visualised using the 73 precursor ion scan presumably as a result of context dependent valine immonium ion formation ${ }^{9}$ and the failure of this fragment to produce an intense $73 \mathrm{amu}$ diagnostic ion. The precursor scan for $\mathrm{m} / \mathrm{z} 103$ (Fig 2C) selected peptides containing glutamate, glutamine and lysine due to the overlap between the immonium ions derived from Glu and Gln and a Lysine derived related low mass ion. This overlap in diagnostic ions allowed identification of all anticipated Lys $\mathrm{C}$ peptides derived from $\mathrm{a}$-synuclein (i.e. peptides $>5 \mathrm{aa}$ in length and not including the large $\mathrm{C}$-terminal fragment which is outside the mass range in these experiments - see Supplementary Table 1) and as such was the best scanning functionality for this particular example. Finally a precursor scan of 131 representing the Lysine immonium ion for which all Lys $\mathrm{C}$ peptides should generate a peak identified all but one anticipated peptide $\left(\mathrm{L}_{6}\right)$ again presumably due to failure of this peptide to yield a 131 immonium ion due to sequence context. Of note this peptide generated a strong 103 precursor scan signal. An example of the MS/MS characterisation of the L4 peptide is shown in Fig 2E. Importantly any falsely selected BSA peptides were readily discriminated once the inappropriately triggered MS/MS spectrum was interrogated due to the unique nature of ${ }^{15} \mathrm{~N}$-fragment ions, thus preventing false selections becoming false positives. Across the three individual precursor scans only 8 BSA peptides triggered an MS/MS experiment while there were 26 a-synuclein selections that covered all of the expected peptides. These data highlight the utility of using more than one precursor scan despite known sequence elements of the peptides, for instance the combination of 131 and 103 identified all anticipated $a$-synuclein Lys $C$ peptides.

\subsection{Using multiple ${ }^{15} \mathrm{~N}$ targeted precursor scans to filter target peptides from a complex mixture}

In the example above ${ }^{15} \mathrm{~N}$ labelled peptides were screened out using a single precursor scan. However, not all naturally processed peptides will contain the specific amino acid used in the precursor ion scan even when overlapping reporter ions, such as the $\mathrm{m} / \mathrm{z} 103$ ion, are used. In addition to the 103 reporter ion, several other low mass ions have been observed in the fragmentation spectra of ${ }^{15} \mathrm{~N}$-labelled peptides that are shared between more than one amino acid residue allowing further potential coverage of peptides in a single experiment (Table 1). Therefore by combining highly specific immonium ions and related ions it is possible to obtain high sequence coverage in a precursor scan experiment. Moreover, using an AB SCIEX 4000 QTRAP mass spectrometer, which can simultaneously monitor a maximum of 4 precursors, we designed multiple precursor scan experiments using low mass target ions that corresponded to amino acids that were known to produce immonium or 
related low mass ions [9] and were distributed as regularly as possible throughout the target protein sequence.

In order to fully assess the feasibility of using multiple precursor scans the complexity of the sample was increased by combining 10 pmol of a dual trypsin and V8 protease digest of ${ }^{15} \mathrm{~N}$ labelled dihydropicolinate synthase (DHDPS) with an unlabelled sample containing $>5000$ peptides at varying concentrations. This unlabelled sample was prepared by acid extraction of cell surface peptides from murine splenocytes, equivalent to $40 \mathrm{ug}$ of total peptide. In this experiment unlabelled peptide was deliberately added in order to try and make it more difficult to specifically select ${ }^{15} \mathrm{~N}$ peptides over the background noise of the unlabelled peptides. A multiple precursor scan targeting m/z 71 (P, D, N), 73 (V, I), 85 and 103 (K,E,Q) was used. As shown in Figure 3, precursors of m/z 491 (red proline immonium ion, aspartic acid and asparagine immonium related ions) and 681.2 (green valine immonium ion, isoleucine immonium related ion) identified DHDPS peptides that were not readily detectable by regular MS, whilst the third precursor identified at 735.5 was abundant in both normal MS and in the NIIPe scan. Another abundant species at 603.1 was manually selected for MS/MS and shown to represent an unlabelled peptide. Thus, the multiple precursor scan was able to selectively filter out labelled peptides in preference to the unlabelled peptides.

\section{$3.3^{15} \mathrm{~N}$ targeted precursor scans identified more target peptides in complex mixtures than regular LC-MS/MS methods}

The data presented in Figures 1-3 collectively highlight the selectivity of NIIPe and its ability to identify isotopically labelled peptides from complex mixtures even when effectively undetectable by conventional untargeted LC-MS/MS. We next sought to compare NIIPe to direct LC-MS/MS analysis of a complex mixture. A small amount (5 pmol - this amount was selected as it provided unambiguous ${ }^{15} \mathrm{~N}$ peptide product ion spectra when using the available standard electrospray source) of ${ }^{15} \mathrm{~N}$ DHDPS trypsin digest was added to a peptide extract from murine splenocytes (as above) in order to create a mixture in which the peptides of interest were at concentrations that prevented untargeted LC-MS/MS detection i.e. buried by the complexity and excess quantity of other peptides. This mixture was then divided into aliquots which were run as either NIIPe scans or regular MS/MS acquisitions with identical LC methodologies on a 4000 QTRAP instrument. Analysis of this mixture using normal LC-MS/MS only identified three peptides originating from the labelled DHDPS following exhaustive manual interrogation of the raw MS/MS data (Table 2). In contrast in the precursor scanning experiments DHDPS peptides were detected and selected for MS/MS based sequencing without manual intervention, allowing highly specific and rapid identification of the target peptides. Thus five peptides derived from the labelled DHDPS peptides were specifically detected and sequenced in the multiple precursor scan. In order to eliminate the impact of the relatively long cycle time (>20s) for the multiple precursor scan, the same sample was analysed in individual precursor scan experiments. This allowed up to nine DHDPS peptides to be identified (Table 2). This time penalty was partially overcome in some experiments by selecting low mass target ions that cover more than one amino acid due to overlap between classical immonium ions and related low mass ions from other amino acids [9-10] (Table 1).

\subsection{The utility of NIIPe methods for DMPK analysis}

Potential applications for this methodology include protein metabolism, bioequivalence and DMPK analyses [14-17]. In order to demonstrate the ability of NIIPe to facilitate such analyses we examined the metabolism of exogenously administered ${ }^{15} \mathrm{~N}$-labelled asynuclein in serum and in murine brain extracts. In these experiments, $5 \mathrm{nmol}$ of ${ }^{15} \mathrm{~N} \mathrm{a}$ synuclein was added to an equal volume of mouse serum or crude murine brain homogenate. Proteins were precipitated and the remaining soluble peptides analysed by mass 
spectrometry. As demonstrated in Figure 4, NIIPe not only demonstrated differences in metabolism of a-synuclein in the brain and serum it allowed the identification of novel peptides derived from this protein as a result of tissue specific endo- and exopeptidase activities (Reilly et al., manuscript in preparation). This differential production of peptide metabolites included differences in the generation of predominantly C-terminal peptides; with KNEEGAPQEGILED found uniquely in the brain extract and TVEGAGSIAAATGFVKK found uniquely in serum and NVGGAVVTGVTAVAQK found in both extracts. Significantly no endogenous a-synuclein peptides were observed despite its high abundance in the brain extract.

\section{Discussion}

We have demonstrated that the use of ${ }^{15} \mathrm{~N}$ immonium ions as targets for a precursor scan can be used to selectively screen out ${ }^{15} \mathrm{~N}$ labelled peptides from a mixture of other unlabelled peptides. Although some ${ }^{15} \mathrm{~N}$-labelled peptides can be detected using standard LC-MS/MS experiments, they were only identified following exhaustive manual interrogation of the several thousand MS/MS spectra recorded in the untargeted analysis of a complex mixture. In contrast the NIIPe scan experiment selected far fewer precursors for subsequent MS/MS analysis. Thus NIIPe demonstrated superior sensitivity and specificity (Figure 3 and Table 2) both in precursor selection and validation, since MS/MS of ${ }^{15} \mathrm{~N}$-labelled material is easily distinguished from inadvertently triggered MS/MS spectrum of unlabelled material post data acquisition. Simultaneous monitoring of multiple diagnostic low mass ions allowed the detection of peptides in complex mixtures that would otherwise be hidden by the complexity of the sample. As the technology and instrumentation continues to develop, we anticipate the capacity to monitor the entire low mass region (50-300 AMU) for all possible diagnostic ions for the isotopically labelled material. Such analysis will allow the detection of all ${ }^{15} \mathrm{~N}$ precursors for subsequent MS/MS characterisation. This ability to broadly scan the low mass region would also allow multiplexing of the experiment to encompass other stable isotope labels. An additional benefit of this would be that by using multiple target ions you reduce the possibility of false selection due to chemical noise, difference in peptide concentrations in the sample, or other contaminants in the sample. The technique is also not simply restricted to immonium ions since other low mass ions that display a diagnostic change in mass for a labelled peptide can be used, for example $\mathrm{y}_{1}$. Moreover the addition of any stable isotope $\left({ }^{13} \mathrm{C},{ }^{2} \mathrm{H}\right.$, etc) will produce diagnostic fragment ions allowing additional scrutiny of other classes of compounds including RNA and DNA and artificially introduced chemical entities such as spacer groups or PEG.

The technique is particularly useful for the analyses of unanticipated species where other techniques such as MRM or targeted analyses are not feasible. The workflow provides new avenues for ADME and DMPK studies [18-23] allowing deeper coverage of metabolites and the capacity to monitor rare species directly ex vivo. Thus, this method does not replace MRM or precursor scanning techniques; instead it is a method that can be used when the assumptions required for the former two techniques cannot be met, providing unparalleled depth of metabolite identification. In the example shown in this manuscript several differentially processed peptides derived from a-synuclein were identified in brain and serum extracts. $a$-synuclein is a small heat stable protein found associated with amyloid deposits in neurodegenerative diseases such as Parkinson's disease [24] and Alzheimer's disease [25]. Of interest one of the peptides identified NVGGAVVTGVTAVAQK, is derived from the fibrillogenic hydrophobic core of a-synuclein that has been shown to facilitate fibril formation in other studies [26]. Several other applications are also under investigation in our laboratories. These include the identification and characterisation of peptide epitopes derived from an exogenous isotope labeled antigen after processing by antigen presenting cells [12] and protein shedding from transplanted tissues and tumor grafts 
as sources of biomarkers and therapeutic targets. Once results from the NIIPe scan are determined further inroads into sensitivity and throughput can be afforded by linking the NIIPe discovery data back to create a set of MRM's for quantitation or further high throughput analysis using workflows such as scheduled MRMs [27-29] on labelled or unlabelled species.

\section{Supplementary Material}

Refer to Web version on PubMed Central for supplementary material.

\section{Acknowledgments}

We thank Drs Nadine Dudek and Andrew Webb for critical reading of the manuscript and Drs Roberto Cappai and Renwick Dobson for isotopically labelled protein expression. AWP is a National Health and Medical Research Council of Australia Senior Research Fellow. The financial support of the Australian Research Council (Linkage project LP0669856), National Health and Medical Research Council of Australia (Project grant 508929) and National Institutes of Health (R01 grants GM057428-06 and NS036592-09) is gratefully acknowledged.

\section{References}

1. Domon B, Aebersold R. Mass spectrometry and protein analysis. Science. 2006; 312:212-217. [PubMed: 16614208]

2. Anderson L, Hunter CL. Quantitative mass spectrometric multiple reaction monitoring assays for major plasma proteins. Mol Cell Proteomics. 2006; 5:573-588. [PubMed: 16332733]

3. Wilm M, Neubauer G, Mann M. Parent ion scans of unseparated peptide mixtures. Anal Chem. 1996; 68:527-533. [PubMed: 8712361]

4. Olsen JV, Mann M. Improved peptide identification in proteomics by two consecutive stages of mass spectrometric fragmentation. Proc Natl Acad Sci U S A. 2004; 101:13417-13422. [PubMed: 15347803]

5. Hager JW, Yves Le Blanc JC. Product ion scanning using a Q-q-Q linear ion trap (Q TRAP) mass spectrometer. Rapid Commun Mass Spectrom. 2003; 17:1056-1064. [PubMed: 12720286]

6. Sandra K, Devreese B, Van Beeumen J, Stals I, Claeyssens M. The Q-Trap mass spectrometer, a novel tool in the study of protein glycosylation. J Am Soc Mass Spectrom. 2004; 15:413-423. [PubMed: 14998545]

7. Steen H, Kuster B, Fernandez M, Pandey A, Mann M. Detection of tyrosine phosphorylated peptides by precursor ion scanning quadrupole TOF mass spectrometry in positive ion mode. Anal Chem. 2001; 73:1440-1448. [PubMed: 11321292]

8. Meiring HD, Soethout EC, Poelen MC, Mooibroek D, et al. Stable isotope tagging of epitopes: a highly selective strategy for the identification of major histocompatibility complex class Iassociated peptides induced upon viral infection. Mol Cell Proteomics. 2006; 5:902-913. [PubMed: 16432254]

9. Hohmann LJ, Eng JK, Gemmill A, Klimek J, et al. Quantification of the compositional information provided by immonium ions on a quadrupole-time-of-flight mass spectrometer. Anal Chem. 2008; 80:5596-5606. [PubMed: 18564857]

10. Falick AM, Hines WM, Medzihradszky KF, Baldwin MA, Gibson BW. Low-mass ions produced from peptides by high-energy collision-induced dissociation in tandem mass spectrometry. Journal of the American Society for Mass Spectrometry. 1993; 4:882-893.

11. Williamson NA, Purcell AW. Use of proteomics to define targets of T-cell immunity. Expert Rev Proteomics. 2005; 2:367-380. [PubMed: 16000083]

12. Purcell AW, Gorman JJ. Immunoproteomics: Mass Spectrometry-based Methods to Study the Targets of the Immune Response. Mol Cell Proteomics. 2004; 3:193-208. [PubMed: 14718575]

13. Williamson, N., Purcell, A., USA 2008

14. Schneider CK, Kalinke U. Toward biosimilar monoclonal antibodies. Nat Biotech. 2008; 26:985990. 
15. Walsh G, Jefferis R. Post-translational modifications in the context of therapeutic proteins. Nat Biotech. 2006; 24:1241-1252.

16. Janiszewski JS, Liston TE, Cole MJ. Perspectives on bioanalytical mass spectrometry and automation in drug discovery. Curr Drug Metab. 2008; 9:986-994. [PubMed: 18991596]

17. Mutlib AE. Application of Stable Isotope-Labeled Compounds in Metabolism and in MetabolismMediated Toxicity Studies. Chemical Research in Toxicology. 2008; 21:1672-1689. [PubMed: 18702535]

18. Wickremsinhe ER, Singh G, Ackermann BL, Gillespie TA, Chaudhary AK. A review of nanoelectrospray ionization applications for drug metabolism and pharmacokinetics. Curr Drug Metab. 2006; 7:913-928. [PubMed: 17168691]

19. Wan H, Holmen AG. High throughput screening of physicochemical properties and in vitro ADME profiling in drug discovery. Comb Chem High Throughput Screen. 2009; 12:315-329. [PubMed: 19275537]

20. Lin ZJ, Li W, Dai G. Application of LC-MS for quantitative analysis and metabolite identification of therapeutic oligonucleotides. J Pharm Biomed Anal. 2007; 44:330-341. [PubMed: 17339091]

21. King R, Fernandez-Metzler C. The use of Qtrap technology in drug metabolism. Curr Drug Metab. 2006; 7:541-545. [PubMed: 16787161]

22. Hsieh Y, Korfmacher W. The role of hyphenated chromatography-mass spectrometry techniques in exploratory drug metabolism and pharmacokinetics. Curr Pharm Des. 2009; 15:2251-2261. [PubMed: 19601826]

23. Carlson TJ, Fisher MB. Recent advances in high throughput screening for ADME properties. Comb Chem High Throughput Screen. 2008; 11:258-264. [PubMed: 18336218]

24. Kazantsev AG, Kolchinsky AM. Central Role of \{alpha\}-Synuclein Oligomers in Neurodegeneration in Parkinson Disease. Arch Neurol. 2008; 65:1577-1581. [PubMed: 19064744]

25. Irvine GB, El-Agnaf OM, Shankar GM, Walsh DM. Protein aggregation in the brain: the molecular basis for Alzheimer's and Parkinson's diseases. Mol Med. 2008; 14:451-464. [PubMed: 18368143]

26. Giasson BI, Murray IVJ, Trojanowski JQ, Lee VMY. A Hydrophobic Stretch of 12 Amino Acid Residues in the Middle of Ît-Synuclein Is Essential for Filament Assembly. Journal of Biological Chemistry. 2001; 276:2380-2386. [PubMed: 11060312]

27. Yocum AK, Gratsch TE, Leff N, Strahler JR, et al. Coupled Global and Targeted Proteomics of Human Embryonic Stem Cells during Induced Differentiation. Mol Cell Proteomics. 2008; 7:750 767. [PubMed: 18304949]

28. Anderson L, Hunter CL. Quantitative Mass Spectrometric Multiple Reaction Monitoring Assays for Major Plasma Proteins. Mol Cell Proteomics. 2006; 5:573-588. [PubMed: 16332733]

29. Keshishian H, Addona T, Burgess M, Kuhn E, Carr SA. Quantitative, Multiplexed Assays for Low Abundance Proteins in Plasma by Targeted Mass Spectrometry and Stable Isotope Dilution. Mol Cell Proteomics. 2007; 6:2212-2229. [PubMed: 17939991]

\section{Abbreviations}

$\begin{array}{ll}\text { ADME } & \text { absorption, distribution, metabolism, and excretion } \\ \text { DMPK } & \text { Drug metabolism/Pharmacokinetics } \\ \text { NIIPe } & { }^{15} \mathrm{~N} \text { Immonium Ion Precursor scanning }\end{array}$




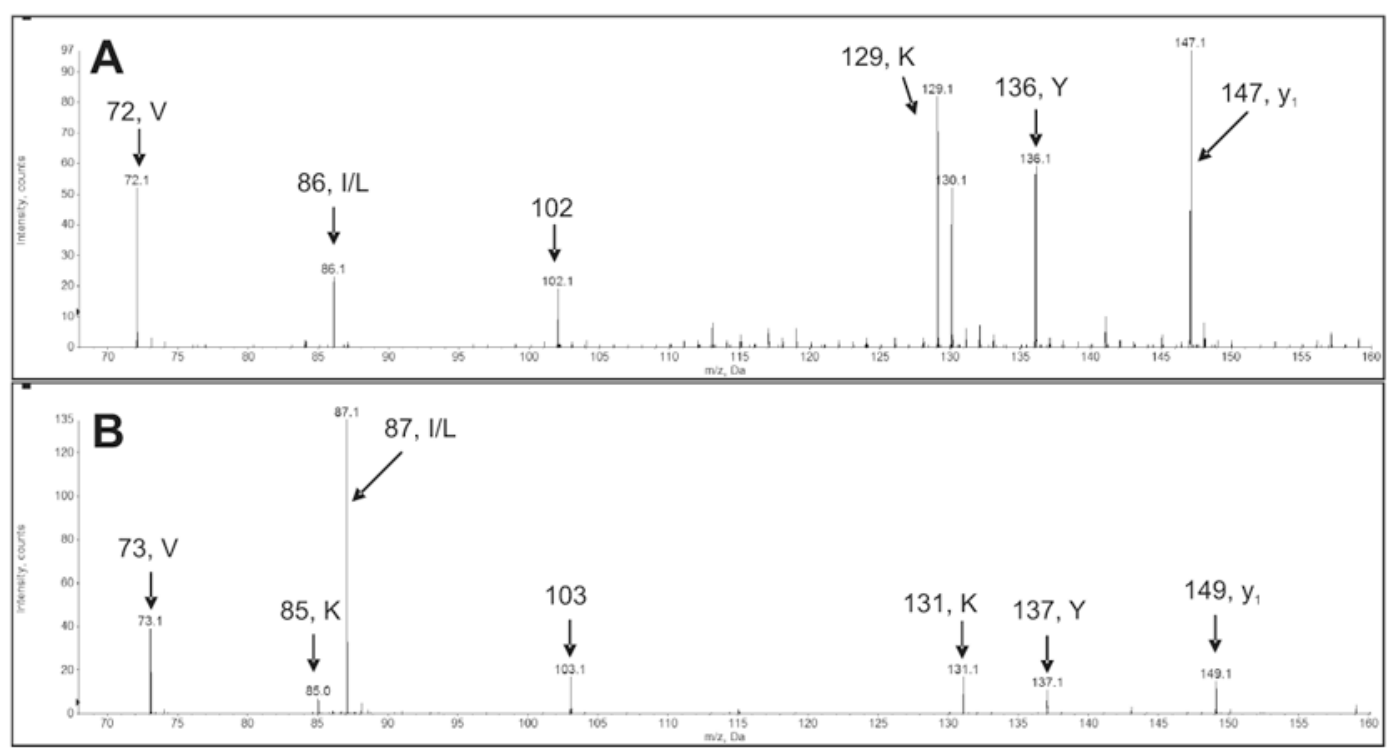

Figure 1.

The low mass product ions for unlabelled and ${ }^{15} \mathrm{~N}$ labelled peptides. (A) spectrum for the low mass product ions for the a-synuclein peptide EGVLYVGSK. When the same peptide is ${ }^{15} \mathrm{~N}$ labelled there is a distinct shift in the low mass product ions as shown in (B) 


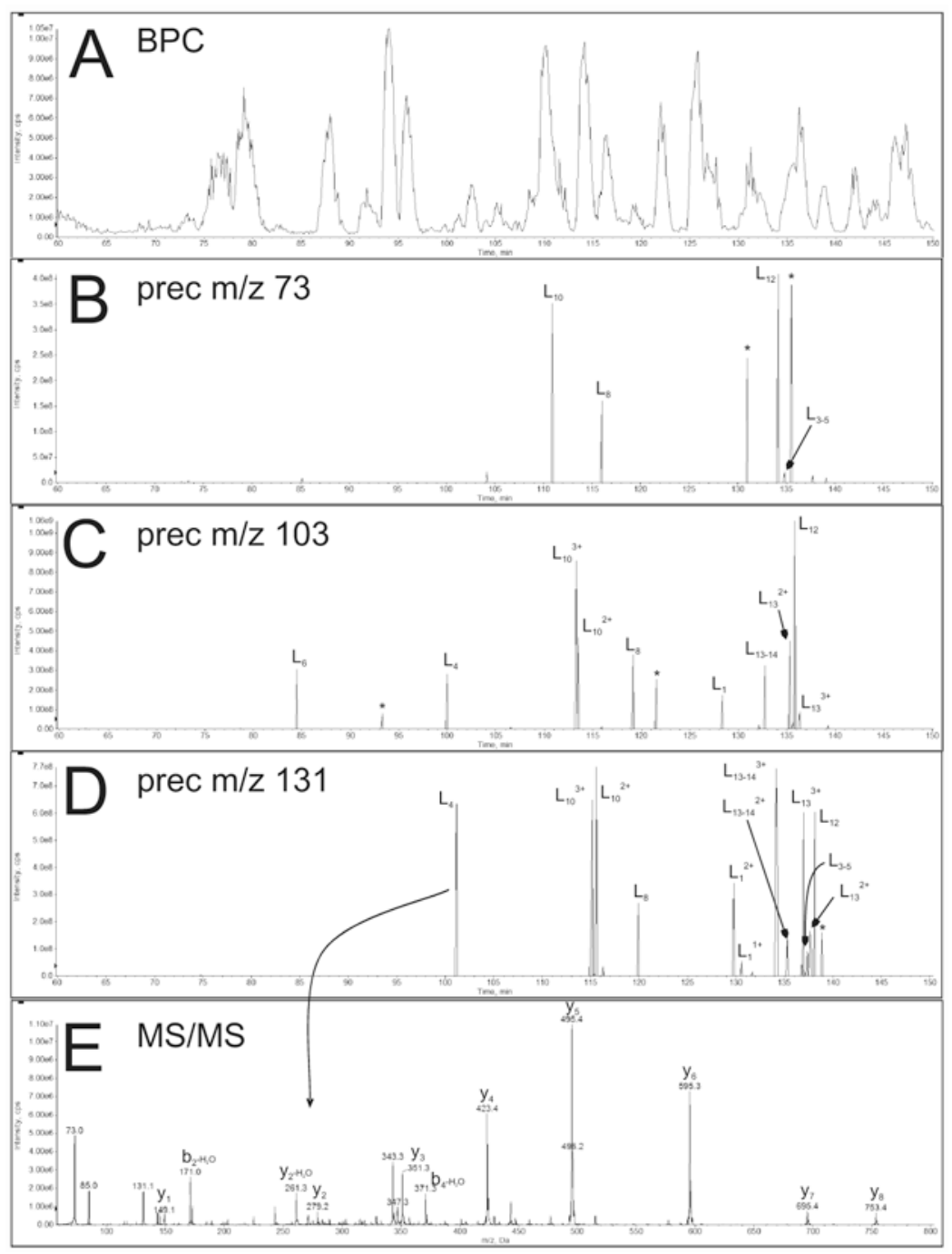

Figure 2.

Precursor ion scanning for ${ }^{15} \mathrm{~N}$ immonium ions. A $1 \mathrm{mg}$ per $/ \mathrm{ml}$ BSA trypsin digest was spiked with and equal volume of $1 \mathrm{mg} / \mathrm{ml}^{15} \mathrm{~N}$ a-synuclein LysC digest. A) The base peak chromatogram for the mixture indicating a complex mix of the two sets of peptides. The automated data acquisition software selected ions from both BSA and a-synuclein for MS/ MS analysis. Using the same sample three separate precursor ion scan experiments were used to specifically target ${ }^{15} \mathrm{~N}$ labeled peptides via low mass ions characteristic of a ${ }^{15} \mathrm{~N}$ labeled amino acid. The masses selected were $\mathrm{m} / \mathrm{z} 73$ for ${ }^{15} \mathrm{~N}$ Valine; 103 corresponding to ions for ${ }^{15} \mathrm{~N}$ Glutamate, Glutamine and Lysine; and 131 corresponding to ${ }^{15} \mathrm{~N}$ Lysine. B), $\mathrm{C}$ ), and D) show the TIC of the product ion scans for each experiment. Peptides derived from ${ }^{15} \mathrm{~N}$ a-synuclein are indicated as $\mathrm{L}_{\mathrm{n}}$ where $\mathrm{n}$ is the LysC peptide number (see Supplementary Table 1). Falsely selected peaks are indicated with an asterisk. Small peaks with no annotation could not be identified due to poor fragmentation spectra. As expected, each of the three precursor scans identified different subsets of the ${ }^{15} \mathrm{~N}$ a-synuclein peptides demonstrating that a standard precursor ion scan would not identify all of the possible peptides in the mix. Hence it is necessary to monitor as many ${ }^{15} \mathrm{~N}$ immonium ions as possible to ensure the best chance of identifying all of the target peptides. E) The MS/MS spectrum of the fourth ${ }^{15} \mathrm{~N}$ a-synuclein LysC peptide (L4, EGVVAAAEK) as captured by the $\mathrm{m} / \mathrm{z} 131$ precursor scan 


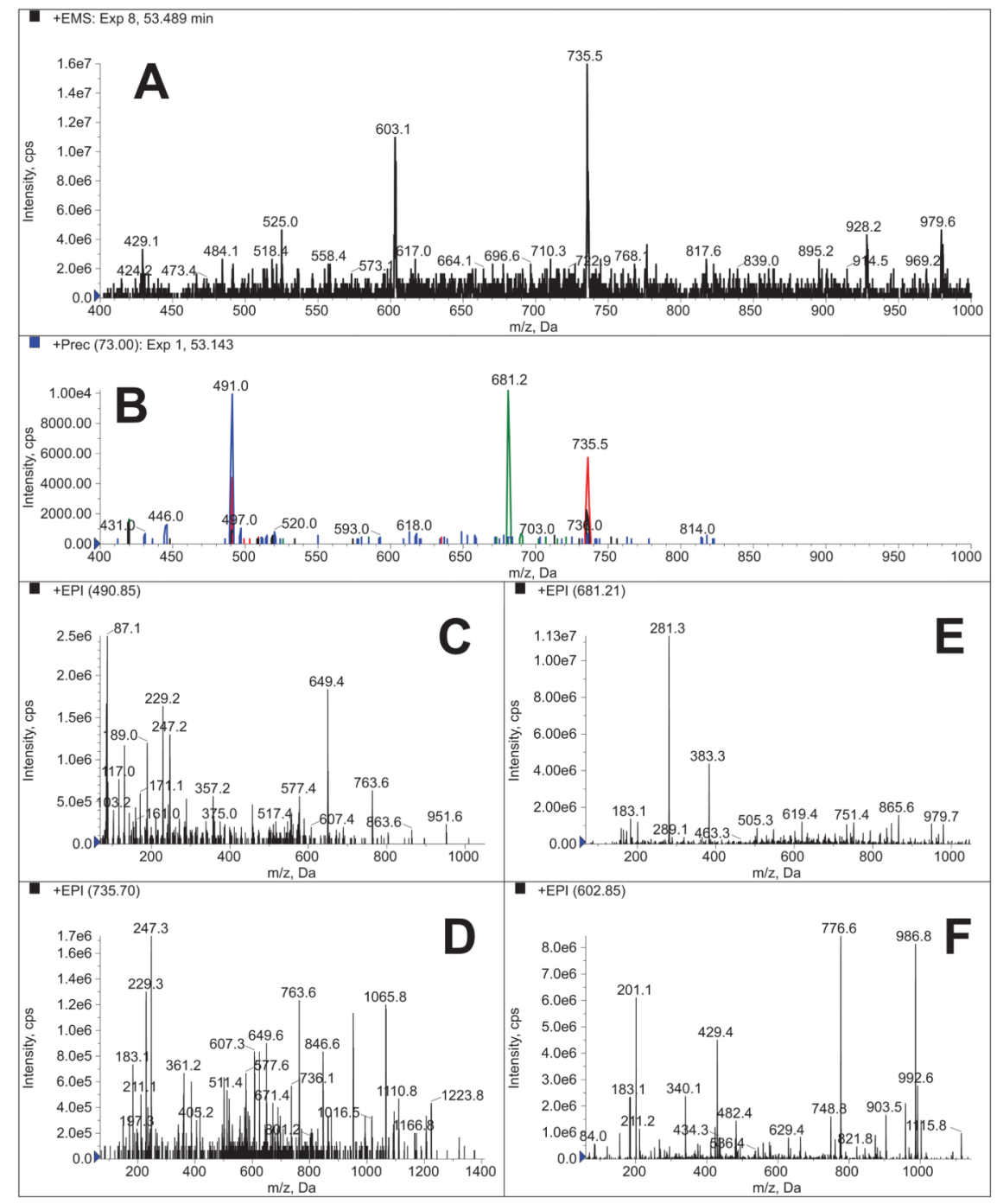

Figure 3.

Scanning ${ }^{15} \mathrm{~N}$ labelled peptides out of a complex mixture. Approximately 10 pmol of ${ }^{15} \mathrm{~N}$ DHDPS was digested with trypsin and added to a very complex mixture of unlabelled peptides ( $\sim 40 \mu \mathrm{g}$ of MHC peptide preparation). Half of this sample was then analysed by regular LC-MS/MS and the other half by a multi precursor ion scan. (A) Shows the mass spectrum of all peptides entering the mass spectrometer for the time point $53.4 \mathrm{~min}$, indicating the presence of several abundant peptides. This enhanced mass spectral survey scan was looped into the precursor ion scan experiment to provide detailed untargeted information about the peptide mixture (B) Shows the precursor scan results corresponding to the same time point. Overlayed are the intensity of ions for the ${ }^{15} \mathrm{~N}$ masses 71 (red), 73 (green), 85 (blue) and 103 (black). The three major peaks in the precursor profile each correspond to ${ }^{15} \mathrm{~N}$ DHDPS peptides that were consequently selected by the precursor scan for further MSMS analysis as shown in C) ${ }^{15} \mathrm{~N} \mathrm{GGQGVISVIANVIPK}^{3+}$, D) ${ }^{15} \mathrm{~N}$ GGQGVISVIANVIPK ${ }^{2+}$, and E) ${ }^{15} \mathrm{~N}$ ALGADAIMLITPY. The final panel F) shows the $\mathrm{ms} / \mathrm{ms}$ spectrum for the unlabelled peptide IVIRFFPLEA. This peptide with a precursor mass of 603.1 is observed in panel A) however it was ignored by the precursor scan experiment. The data shown in F) was extracted from the previous LC-MS/MS run on the same sample. 


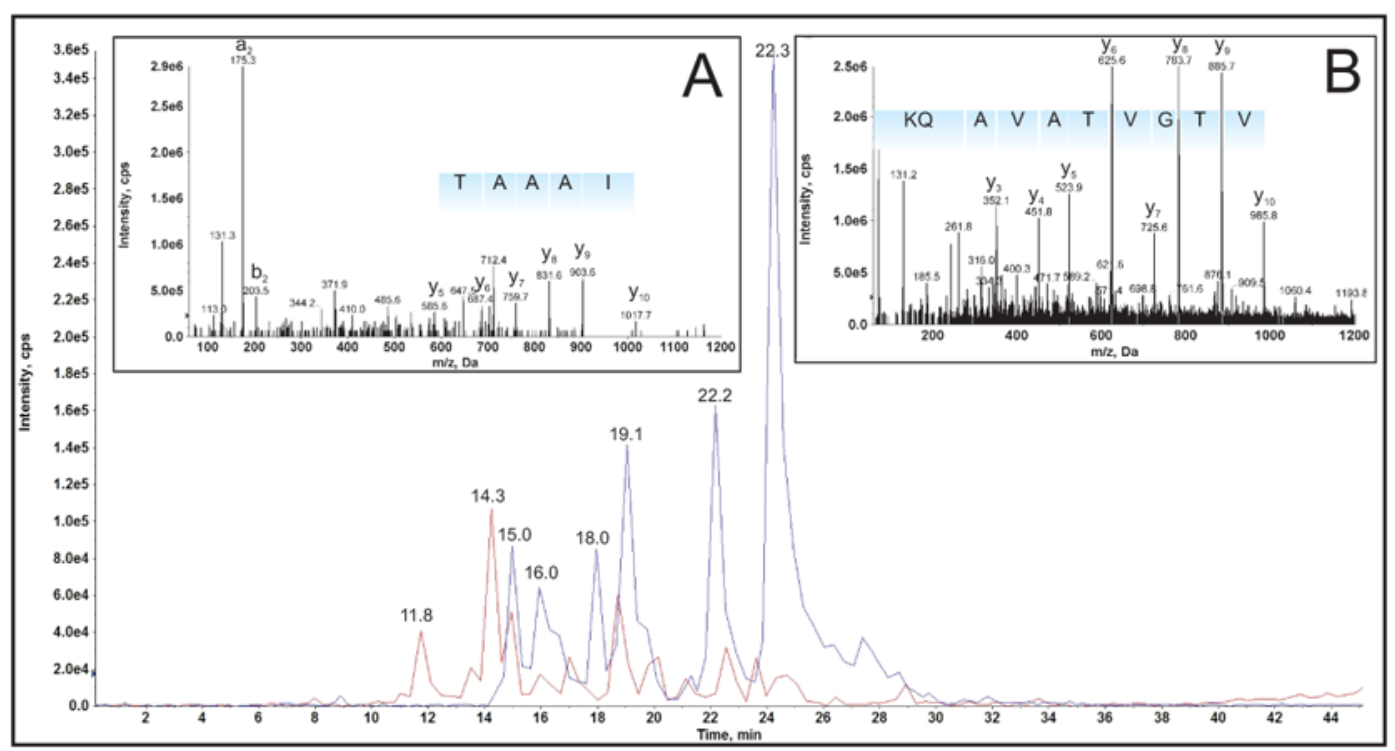

Figure 4.

Using NIIPe to search for peptides of ${ }^{15} \mathrm{~N}$ a-synuclein after incubation for $5 \mathrm{~min}$ in serum or brain extract. $5 \mathrm{nmol}$ of ${ }^{15} \mathrm{~N}$ a-synuclein was added to $1 \mathrm{ml}$ of neat serum or $1 \mathrm{ml}$ of crude brain homogenate ( 1 mouse brain homogenised in TBS to a volume of $1 \mathrm{ml}$ ). Proteins were precipitated by TCA and then $5 \mu \mathrm{l}$ of the remaining soluble fraction was analysed using $\mathrm{m} / \mathrm{z}$ 85 and 73 as target ions for a dual precursor scan. The TIC for the precursor scan for $\mathrm{m} / \mathrm{z} 85$ is shown for the brain (blue) and the serum sample (red). A number of ${ }^{15} \mathrm{~N}$ labelled peptides were screened from the samples including the two peptides shown in the inset. A) is the ${ }^{15} \mathrm{~N}$ labelled peptide TVEGAGSIAAATGFVKK while B) the second peptide is based on the peptide NVGGAVVTGVTAVAQK, however as shown in the figure despite an excellent sequence tag for the central part of the peptide the observed precursor mass of did not correspond to the predicted mass of the ${ }^{15} \mathrm{~N}$ labelled version of the peptide. There was insufficient information in the spectrum to formally identify the modification. This is a prime example of an unexpected peptide that would not ordinarily be predicted and therefore observed by MRM techniques. 
Table 1

List of immonium ions and the corresponding ${ }^{15} \mathrm{~N}$ labelled immonium ions

\begin{tabular}{|c|c|c|c|}
\hline Residue 3-letter code & 1-letter code & Immonium ion* & ${ }^{15} \mathrm{~N}$ Immonium ion* \\
\hline Glycine, Gly & G & 30 & 31 \\
\hline Alanine, Ala & A & 44 & 45 \\
\hline Serine, Ser & $\mathrm{S}$ & 60 & 61 \\
\hline Proline, Pro & $\mathrm{P}$ & 70 & 71 \\
\hline Valine, Val & $\mathrm{V}$ & 72 & 73 \\
\hline Threonine, Thr & $\mathrm{T}$ & 74 & 75 \\
\hline Cysteine, Cys & $\mathrm{C}$ & 76 & 77 \\
\hline Isoleucine, Ile & I & 86 & 87 \\
\hline Leucine, Leu & $\mathrm{L}$ & 86 & 87 \\
\hline Asparagine, Asn & $\mathrm{N}$ & 87 & 89 \\
\hline Aspartic acid, Asp & $\mathrm{D}$ & 88 & 89 \\
\hline Glutamine, Gln & Q & 101 & 103 \\
\hline Lysine, Lys & K & 101 & 103 \\
\hline Glutamic acid, Glu & E & 102 & 103 \\
\hline Methionine, Met & M & 104 & 105 \\
\hline Histidine, His & $\mathrm{H}$ & 110 & 113 \\
\hline Phenylalanine, Phe & $\mathrm{F}$ & 120 & 121 \\
\hline Arginine, Arg & $\mathrm{R}$ & 129 & 133 \\
\hline Tyrosine, Tyr & $\mathrm{Y}$ & 136 & 137 \\
\hline Tryptophan, Trp & W & 159 & 161 \\
\hline
\end{tabular}




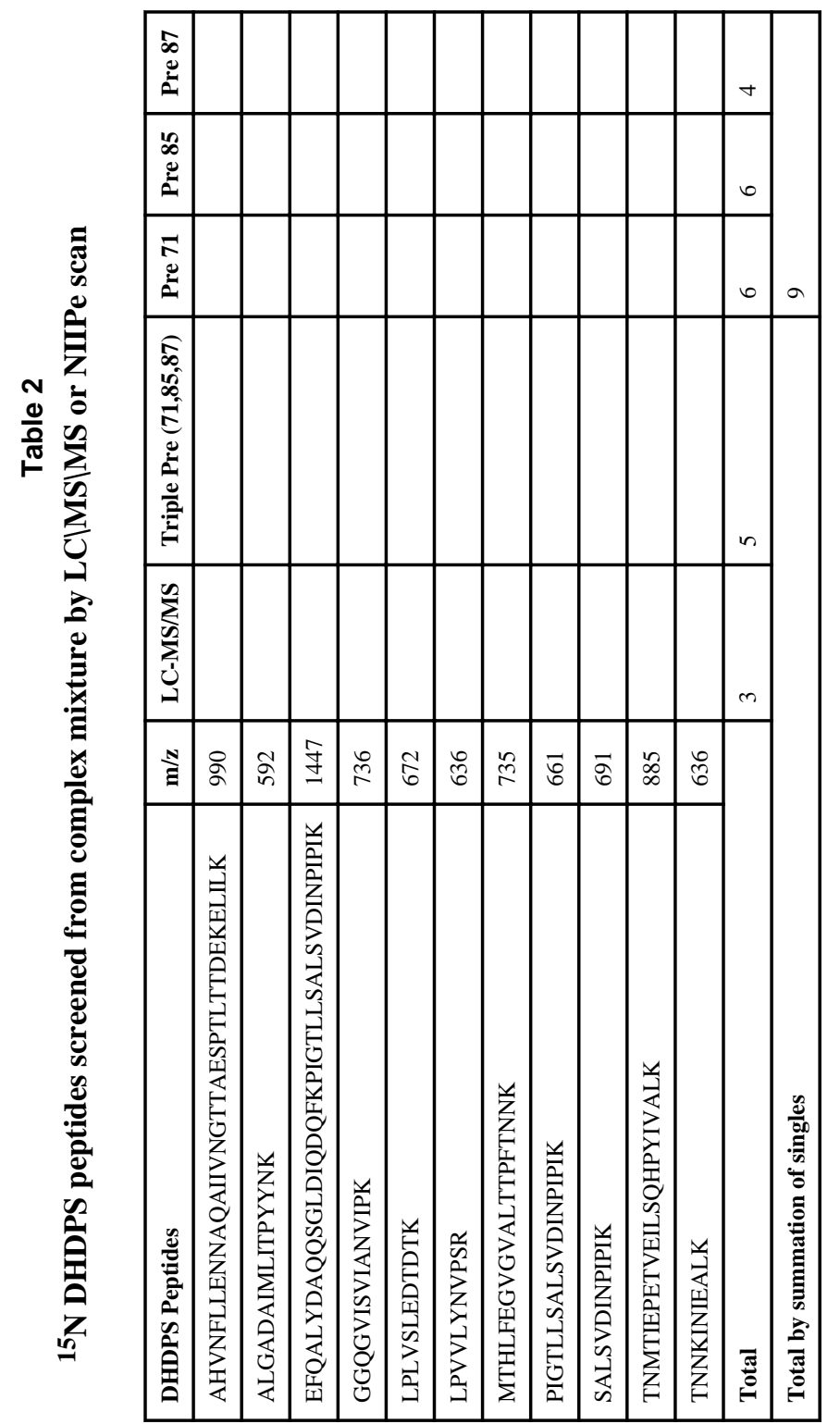

Proteomics. Author manuscript; available in PMC 2012 July 24. 